SSCP pattern was found in both subjects, and therefore they did not have the mutation present in their relatives (fig 2). However, there is still a possibility that II:6, and therefore III: 10, are carriers of Fabry disease.

As patients with variant (cardiac) Fabry disease present mainly with cardiac symptoms resulting from cardiomyopathy, and because these patients have none or a mild form of the renal symptoms characteristic of the classic form of the disease, the correct diagnosis may be missed. The variant form is rare but may account for a few of the numerous cases of cardiac disease in men and should be considered when several cases of cardiac disease occur within a single family.

We thank Elsebeth Lund Christensen and Minna Becher for excellent technical assistance. This study was financially supported by the Danish Medical Research Council, Købmand i Odense Johann og Hanne Weimann f. Seedorffs legat, Signe and Peter Gregersens Mindefond and Novo's Fond.

1 Desnick RJ, Ioannou AI, Eng CM. $\alpha$-Galactosidase A deficiency: Fabry disease. In: Schriver CR, Beaudet AL, Sly
WS, Valle D, eds. The metabolic and molecular basis of inherWS, Valle D, eds. The metabolic and molecular basis of inher-
ited disease. 7th edn. New York: McGraw-Hill, 1995:

2 Komreich R, Desnick RJ, Bishop DF. Nucleotide sequence of the human $\alpha$-galactosidase A gene. Nucleic Acids Res
1989;17:3301-2.

3 Eng CM, Desnick RJ. Molecular basis of Fabry disease: Mutations and polymorphisms in the human $\alpha$-galactosidase A gene. Hum Mutat 1994;3:103-11.

4 Ploos van Amstel JK, Jansen RPM, de Jong JGN, Hamel BCJ, Wevers RA. Six novel mutations in the $\alpha$-galact, Wevers RA. Six novel mutations in the $\alpha$-galGenet 1994;3:503-5.

5 Davies J, Christomanou H, Winchester B, Malcolm S. Detection of 8 new mutations in the $\alpha$-galactosidase A gene in Fabry disease. Hum Mol Genet 1994;3:667-9.

6 Meaney C, Blanch LC, Morris P. A nonsense mutation $(\mathrm{R} 220 \mathrm{X})$ in the $\alpha$-galactosidase A gene detected in a female carrier of Fabry disease. Hum Mol Genet 1994;3:1019-20.

7 Eng CM, Niehaus DJ, Enriquez AL, Burgert TS, Ludman MD, Desnick RJ. Fabry disease: twenty-three mutations including sense and antisense $C P G$ alterations and identifiincluding sentifcation of a deletional hot-spot in the $\alpha$-galactosidase

8 Madsen KM, Hasholt L Sarensen SA, Fermér ML, Dahl $\mathrm{N}$. Two novel mutations (L32P) and (G85N) among five different missense mutations in six Danish families with Fabry's disease. Hum Mutat 1995;5:277-8.

9 Hasholt L, Sørensen SA, Wandall A. Clinical and biochemical findings in an atypic Fabry's disease hemizygote [abstract]. Vth International Congress of Inborn Errors of Metabolism. 1990.

10 Desnick RJ, Allen KY, Desnick SJ, Raman MK, Bemlohr RW, Krivit W. Fabry's disease: enzymatic diagnosis of hemizygotes and heterozygotes. 7 Lab Clin Med 1973;81: 157-71.

11 Kösel S, Graeber MB. Use of neuropathological tissue for molecular genetic studies: parameters affecting DNA extraction and polymerase chain reaction. Acta Neuropathol extraction and poly

12 Ishii S, Sakuraba H, Suzuki Y. Point mutation in the upstream region of the $\alpha$-galactosidase A gene exon 6 in an atypica variant of Fabry disease. Hum Genet 1992;89:29-32.

\title{
Novel primer specific false terminations during DNA sequencing reactions: danger of inaccuracy of mutation analysis in molecular diagnostics
}

\author{
R Anwar, A Booth, A J Churchill, A F Markham
}

Molecular Medicine Unit, University of Leeds, Department of Medicine, Clinical Sciences Building, St James's University Hospital,

Leeds LS9 7TF

Correspondence to: Dr R Anwar.

email:

msjra@stjames.leeds.ac.uk

Accepted for publication 18 July 1996

\begin{abstract}
The determination of nucleotide sequence is fundamental to the identification and molecular analysis of genes. Direct sequencing of PCR products is now becoming a commonplace procedure for haplotype analysis, and for defining mutations and polymorphism within genes, particularly for diagnostic purposes. A previously unrecognised phenomenon, primer related variability, observed in sequence data generated using Taq cycle sequencing and $\mathbf{T} 7$ Sequenase sequencing, is reported. This suggests that caution is necessary when interpreting DNA sequence data. This is particularly important in situations where treatment may be dependent on the accuracy of the molecular diagnosis.
\end{abstract}

(F Clin Pathol: Mol Pathol 1996;49:M312-M314)

Keywords: novel primer specific terminations, DNA sequencing, molecular diagnostics.
In the field of human genetics, every disorder studied at the molecular level requires nucleotide sequence determination. The information obtained from mutation analysis is often essential for understanding the structure and function of the proteins encoded by the genes under study. Identification of mutation(s) in a particular gene, which consistently segregates with the disease phenotype in pedigrees, provides proof that a given candidate gene is really the 'disease' gene in a specific inherited condition. The accuracy of mutation analysis is especially important for prenatal diagnosis where the continuation of a pregnancy may be dependent on the results of the molecular assay.

The dideoxy chain terminator DNA sequencing method is the most popular procedure because of its practical simplicity. It was originally described by Sanger et al ${ }^{1}$ and many modifications to the original protocol have been introduced over the years. The two most common methods of DNA sequencing at 


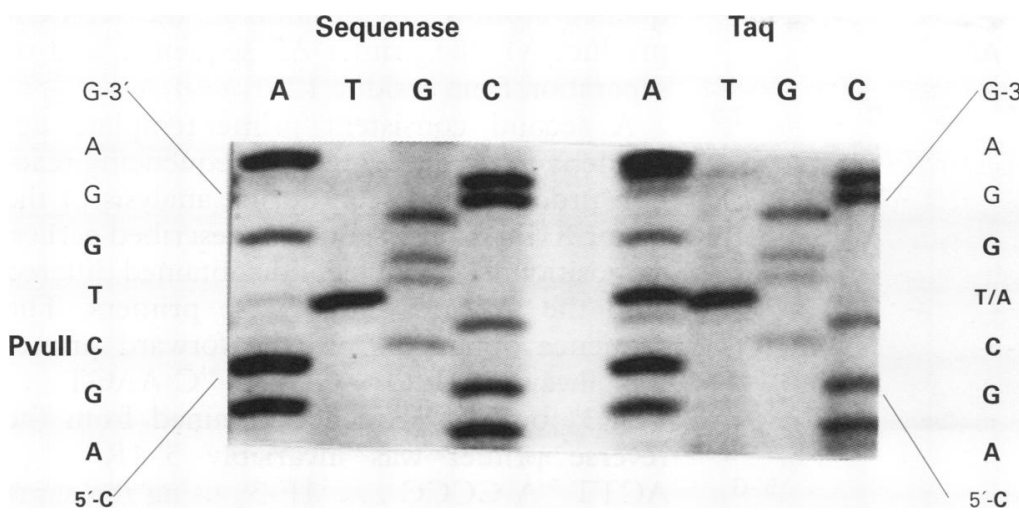

Figure $1 \quad P C R$ and RT-PCR were performed as previously described. ${ }^{4} P C R$ products were purified using Wizard DNA clean-up columns (Promega) following the manufacturer's protocol. Two methods for generating sequence reaction products were used. (1) Cycle sequencing: 25-50 fmoles of purified PCR product was sequenced directly using the Promega fmol cycle sequencing kit and $\gamma^{32} P$ end-labelled sequencing primer, as described by the manufacturers. (2) Sequenase sequencing: the T7 DNA polymerase Sequenase Version 2.0 kit (USB) was used with the following protocol. The sequencing primer was end-labelled as for cycle sequencing; 2 pmoles of labelled primer was annealed to $250 \mathrm{ng}$ of $P C R$ product, in $1 \times$ Sequenase buffer in a 10 pl volume, by incubation at $100^{\circ} \mathrm{C}$ for five minutes followed by immediate quenching in dry icelethanol for five minutes. The tubes were microcentrifuged briefly to collect all condensate at the bottom. Sequenase enzyme mix (5.5 $\mu l$ ) (containing $7 \mu \mathrm{l} \mathrm{TE}, 10 \mu \mathrm{l}$ water, $4 \mu \mathrm{l} 0.1 \mathrm{M} \mathrm{DTT}$, and $1 \mu \mathrm{l}$ Sequenase) was added to the annealed primer and template. This mixture $(3.5 \mu l)$ was then aliquoted to tubes, or microtitre tray wells, containing $2.5 \mu \mathrm{l}$ of each of the ddNTP termination mixes. DNA polymerisation was performed at $37^{\circ} \mathrm{C}$ for 10 minutes. Reactions were terminated by addition of $4 \mu$ formamide loading buffer. Sequencing reaction products from all reactions were analysed on buffer gradient gels followed by autoradiography. This figure illustrates the factor XIIIa exon 1 sequence observed with the $1 R$ primer using the same PCR product template in Sequenase and Taq cycle sequencing. The T/A observed with Taq cycle sequencing is at position 176 from primer $1 F$ and at position 208 from primer $1 R$.

present are the use of T7 DNA polymerase (Sequenase) and cycle sequencing using a thermostable DNA polymerase. The latter method has the particular advantage of requiring only fmoles of template DNA and is thus becoming the method of choice. Here, we present novel data on inherent primer related problems associated with DNA polymerases, which may lead to false sequencing results and discuss the level of caution necessary when undertaking molecular diagnosis.

\section{Sequences analysed}

Template DNA was generated by PCR and sequenced directly using Sequenase and Taq cycle sequencing. (1) Exon 1 of the factor XIIIa gene ${ }^{2}$ was amplified using primers $1 \mathrm{~F}$ (5'-dTACTCCCAGCAACTGGTTG-3') and 1R (5'-dCTGGCTCATAGGGTGCAC-3') to yield a PCR product of 383 base pairs (bp). (2) RT-PCR products corresponding to nucleotides 80 to 761 (codons 1 to 225 ) in the factor XIIIa cDNA ${ }^{3}$ were amplified from a normal (A1) and factor XIIIa deficient patient (A2) RT-PCR products $A 1$ and $A 2$ were generated, from cDNA, using oligonucleotides $\mathrm{AF}$ (forward primer: 5'-dCAAAAATGTCAGAAACTTCC-3') and AR (reverse primer: 5'-dCAGCTTCTGGTCTTGATGT-3'). Each product was directly sequenced using primers $A F, A R$, AFn (5'-dAGGACCGCCTTTGGAGGC-3') which is nested immediately $3^{\prime}$ to $A F$, and ARn (5'-dAATTACCCCGATGTCATT-3') which is nested by 19 bases $3^{\prime}$ to AR.

RT-PCR product $A 1$, from a normal subject, is $682 \mathrm{bp}$ long and encompasses exons 2 to 5 of factor XIIIa cDNA ${ }^{3}$. RT-PCR product A2 is $493 \mathrm{bp}$ long, and is generated from a factor
XIIIa deficient patient carrying a mutation at the exon 3/intron 3 splice junction. ${ }^{4}$ This mutation results in exon 3 being skipped during RNA processing. ${ }^{4}$ Hence, RT-PCR product A2 lacks exon 3 sequence and is consequently shorter by 189 bp than the Al RT-PCR product. All 'incorrect' sequence data described herein could be consistently and reproducibly generated.

\section{Results and Discussion}

To ensure accuracy of data, DNA sequence analysis is always carried out both on the forward and reverse strands. Accuracy becomes an issue when forward and reverse strand sequencing generates contradictory results, particularly during mutation analysis in molecular diagnostics. This can sometimes be resolved by using a DNA polymerase of higher fidelity. We have observed a number of such instances and present one from analysis of exon 1 of the factor XIIIa gene. ${ }^{2}$ During Taq cycle sequencing, the correct expected sequence was obtained with the forward primer $1 F$, but sequence analysis of the second strand using the reverse primer $1 R$ gave two bands at position 176 , giving the sequence $5^{\prime}-1 R^{383} \ldots$ $\mathrm{C}^{180}$ AGC T/A ${ }^{176} \mathrm{GGA}^{173} \ldots \mathrm{F}^{1}-3^{\prime}$ (fig 1 ). When the same PCR products were sequenced using T7 DNA polymerase (Sequenase sequencing) and the reverse primer $1 \mathrm{R}$, the misincorporation at position 176 was not observed (fig 1), stressing the higher accuracy of T7 DNA polymerase.

Taq DNA polymerase is known to have a higher misincorporation rate compared with other DNA polymerases, ${ }^{6}$ and the misincorporated bases are thought to be random. However, in cycle sequencing using Taq, the sequencing reaction products are not created by an amplification procedure. Thus, misincorporation in sequencing reactions does not have a significant effect on the final result, unless the dideoxynucleotide misincorporation is consistently at the same nucleotide in a major proportion of the sequencing template fragments in the reaction. It is only in PCR that errors during the early cycles can amplify and lead to errors in the end product. It is probable that the misincorporation seen with Taq cycle sequencing in fig 1 is not a random process, but may be specifically dependent on some as yet unknown local conformational factor. Also, the misincorporation may be influenced by the presence of the restriction enzyme PvuII palindromic sequence (fig 1 ).

Bands at the same position in two or three lanes, occurring at specific regions, are often due to band compression where a DNA strand is forming secondary structure during gel electrophoresis, leading to anomalous migration. ${ }^{7}$ This cannot be the explanation for the misincorporation band seen with Taq cycle sequencing, in lane $\mathrm{A}$ in fig 1 , as this band is clearly not present in the Sequenase sequencing reaction products analysed on the same gel.

RT-PCR products A1 and A2, described above, generated the same results when sequenced directly using Sequenase or Taq cycle 
A1

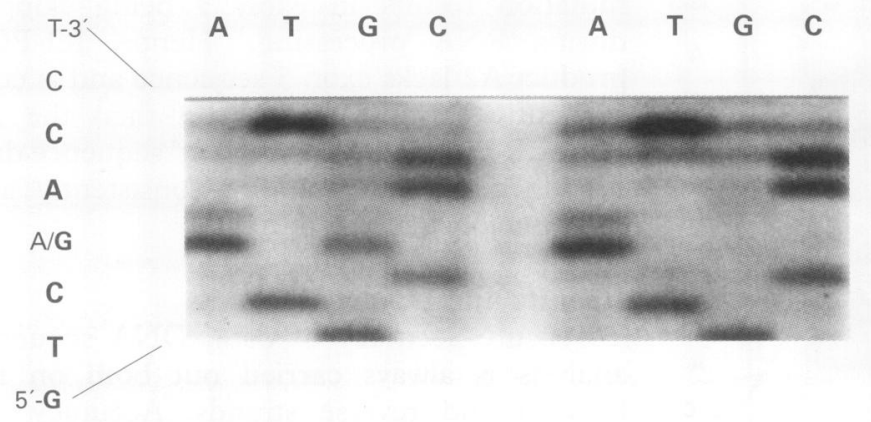

quence around this position in the RT-PCR product $\mathrm{A} 1$, the primer $\mathrm{AF}$ sequence, and its separation from residue 126 .

A second consistent primer/template dependent effect on Sequenase sequencing reaction products was seen during analysis of the factor XIIIa exon 1 sequence described earlier. At position 94 the nucleotide obtained differed with the forward and reverse primers. The sequence obtained from the forward primer was always $5^{\prime}-1 \mathrm{~F}^{1} \ldots$. GGGG ${ }^{94} \mathrm{C}$ AAGT . . ${ }^{383} 1 \mathrm{R} 3$ ', but the sequence obtained from the reverse primer was invariably $5^{\prime}-1 R^{383} \ldots$ ACTT ${ }^{94} \mathrm{~A}$ CCCC . . . '1 $1 \mathrm{~F}-3$ ', using the same sequencing substrate (data not presented).

In summary, our data show that both Seque-
A1

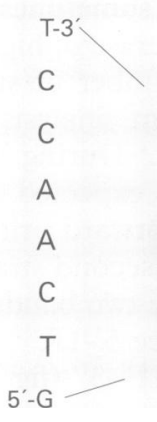

A2

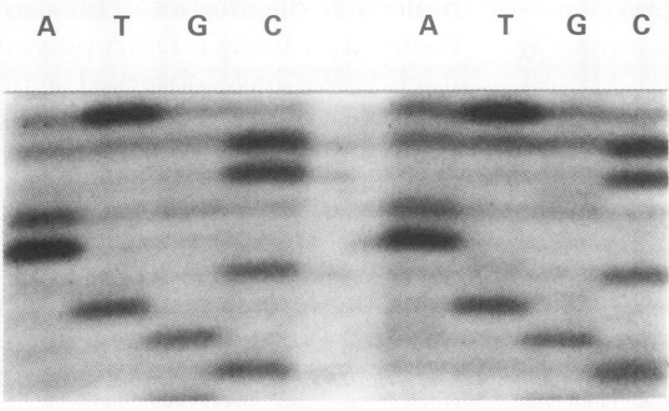
nase and Taq DNA polymerases can generate consistently and reproducibly incorrect sequence data. The inaccuracy observed may be influenced by a combination of primer sequence, the local conformation around the site of misincorporation and the distance between the primer and the termination point. The primer related sequence errors seem more likely to occur with Taq DNA polymerase than with Sequenase.

Although the consistent misincorporation products described herein all involve addition of dideoxy nucleotide residues, which are known to have very different enzyme affinities to their dNTP counterparts, the phenomenon observed is sufficiently worrying to warrant comment. We are not aware that this highly specific effect has been described previously. Thus, it may be advisable to perform two independent assays for molecular diagnosis-for example, sequence and restriction analysis. In situations where a restriction site does not exist around the mutation site, and sequence analysis using forward and reverse primers gives contradictory results, it may be necessary to determine nucleotide sequence with a different, third sequencing primer. This would be particularly important in prenatal diagnosis where the decision to proceed with the pregnancy will generally depend on the diagnostic result obtained.

Work in our laboratories is supported by the Medical Research Council, Wellcome Trust, Northern and Yorkshire Regional Health Authority, West Riding Medical Research Trust, and Yorkshire Cancer Research Campaign.

Hence, the expected sequence was obtained. Also, sequence analysis of products $\mathrm{A} 1$ and $\mathrm{A} 2$ with the reverse primers $A R$ and $A R n$ confirmed that both products are homozygous at base 126. Thus, there is not a consistent PCR derived misincorporation present in these sequencing substrates and Sequenase can consistently catalyse specific incorrect termination which is primer dependent (present with $\mathrm{AF}$, absent with AFn).

GTCGAC is a recognition sequence for the restriction enzyme Sall. Digestion of products $\mathrm{A} 1$ and $\mathrm{A} 2$ resulted in fragments correlating with the expected sequence (data not shown), thus confirming the absence of a Sall site around position 126 in Al (fig $2 \mathrm{~A}$ ). The 'false stop', G, seen at base 126 thus results from a combination of the specific nucleotide se-
1 Sanger F, Nicklen S, Coulson AR. DNA sequencing with chain-terminating inhibitors. Proc Natl Acad Sci USA 1977;74:5463-7.

2 Ichinose A, Davie EW. Characterisation of the gene for the $\alpha$ subunit of factor XIII, a blood coagulation factor. Proc Natl Acad Sci USA 1988;85:5829-33.

3 Grundmann U, Amann E, Zettlmeissl G, Kupper HA. Characterisation of cDNA coding for human factor XIIIa. Proc Natl Acad Sci USA 1986;83:8024-8.

4 Anwar R, Stewart AD, Miloszewski KJA, Losowsky MS, Markham AF. Molecular basis of inherited factor XIII deficiency, identification of multiple mutations provides . insights

5 Biggin MD, Gibson TJ, Hong GF. Buffer gradient gels and ${ }^{5} S$ label as an aid to rapid DNA sequence determination. Proc Natl Acad Sci USA 1983;80:3963-6.

6 Cha RS, Thilly WG. Specificity, efficiency, and fidelity of PCR. PCR Methods and Applications 1993;3:18-29.

7 Ward ES, Howe CJ (eds). Trouble shooting in chaintermination DNA sequencing. In: Nucleic acid sequencing: $a$ practical approach. Oxford: IRL Press, 1989:79-98. 